\title{
Low-crested offshore breakwaters: a functional tool for beach management
}

\author{
K. Spyropoulos \& E. Andrianis \\ TRITON Consulting Engineers, Greece
}

\begin{abstract}
Beach best quality is one of the main targets for resort hotels located near to or by the sea. Offshore breakwaters are an alternative for coast protection against erosion and/or the creation of pocket beaches, particularly at locations where the tidal range is negligible or small. Such works can successfully function only under specific combinations of wave, longshore and cross shore current, bathymetry and quantity/quality of sediment. Hereunder the approach methodology for the design of low-crested offshore breakwaters for two hotels in Greece and Cyprus is described.

Keywords: offshore breakwaters, beach management, erosion control, coastal protection.
\end{abstract}

\section{Introduction}

Offshore or detached breakwaters are used extensively for coast protection or the creation of crescentic beaches with success particularly on coastlines where the tidal range is negligible or small. The presence of a system of offshore breakwaters influence the propagation of waves, causing partial wave breaking on the breakwaters' offshore slope, but also allow wave propagation only through overtopping and diffraction between the gaps. This procedure results to wave energy reduction at the lee side of the breakwaters as well as local patterns of wave-induced currents. Consequently both alongshore and crossshore sediment transport is reduced leading to sediment deposition and accretion in the sheltered area between the structures and the shoreline. The target shoreline configuration is the formation of a salient (an advance of the water line behind the structure), or a tombolo (connection of the shoreline and the breakwaters). 
Hence offshore breakwaters can be designed to retard erosion on an existing beach, promote natural sedimentation to form a new beach, increase the longevity of a beach fill and maintain a wide beach for storm damage reduction and recreation. Unlike cross-shore structures such as groins, which may impound sediment, properly designed breakwaters can allow continue movement of longshore transport through the project area, thus reducing adverse effects on the downdrift side. Effects on adjacent beaches are further minimized when nourishment is included in the project.

\section{Design principles}

Offshore breakwaters are generally sited with their major axis parallel to the coastline, thus intercepting incident wave energy so that both alongshore and onshore-offshore sediment transport is reduced. The primary influence is that of wave diffraction which not only reduces wave heights in the lee of the structure, but also creates wave height gradients that drive wave-induced currents towards the sheltered area. Thus in both instances the trend is towards the transportation of sediment to the center of the shoreward side of the structures. The net result is the growth of a salient or a tombolo.

The resulting shoreline configuration depends on many factors, including the longshore sediment transport rate, sediment supply, sediment size, underwater beach slope structure length, gap distance from shore, depth at structure and the structure's crest height.

When properly designed, the formation of a sand salient begins soon after construction of the breakwater. Approx. 25 to $50 \%$ of the sand volume may be deposited in the first year, with a steady state usually being reached after three to four years. After that time, the system will remain relatively stable, undergoing minor or moderate seasonal changes.

Design procedures are largely empirical and vary from project to project. This has resulted in highly successful projects in most cases however some projects have experienced beach erosion on the downstream side of the breakwaters. Additional research both in the laboratory and in the field is needed to develop more comprehensive design criteria.

An offshore breakwater can be constructed as a single structure for localized shore protection or as multiple breakwaters to protect a longer section of beach. Spacing between breakwater segments (gap width) should be carefully evaluated by increasing the gap width according to the amount of wave energy behind the breakwaters.

Offshore breakwaters are often constructed as rubble-mound breakwaters of trapezoidal cross-section, having different slope angles on the seaward and shoreward sides. The slope angle of a breakwater depends on the forces exerted by the waves. Under breaking waves on the seaward side a mound is subjected to impact forces. Steep slopes result to rise in reflection-caused velocities and eddies at the last foot of the structure, this in turn causing local scour and settlement of the structure. Flat slopes give rise to energy dissipation on a longer section of structure. 


\section{Design procedure}

The design of an offshore breakwaters system should encompass the following considerations:

\subsection{General aspects}

- Purpose of the project

- Functional requirements

- Project constraints/material/labor/equipment/ time/finance

- Overall description of boundary conditions

\subsection{Preparation of alternative general solutions}

\subsection{Determination of boundary conditions}

- Hydraulic: water levels, wave climate, currents morphology etc

- Geotechnical: soil type and relevant parameters

- Other relevant conditions and loads: earthquake, vegetation, etc

\subsection{Feasibility studies for generated alternatives:}

- Detect suitable structural configurations (geometry)

- Review the possible failure mechanisms

- Select a suitable armour alternative and size of armour units

- Make preliminary feasibility analysis of alternatives, develop cost estimate for each alternative and evaluate construction requirements and limitations of alternatives.

- Select the final solution

\subsection{Final design}

- Consider the use of models

- Consider the probabilistic approach

- Make final estimation and evaluation of the structure geometry

- Design the final dimensions of the structure including prediction of scour and design toe protection and transitions.

- Check for possible failure mechanisms of the final design, including risk

- Go through the overall project and checklist for final control

- Prepare specifications for materials /equipment/cost/quality control.

\subsection{Structural failure control}

Although all categories of events which may cause the inundation of a land or damage of structure are equally important for the overall safety, the engineer's responsibility is mainly limited to the technical and structural aspects. In the case of coastal structures the following major events can be distinguished: 
- overflow or overtopping of the structure (i.e. instability of the superstructure)

- $\quad$ erosion or instability of slopes

- instability of inner section leading to progressive failure

- scour and instability of toe-protection

- $\quad$ instability of the foundation and internal erosion (i.e. piping)

- instability of the whole structure

\section{Case studies}

\subsection{Hotel "AKTI LAKOPETRA" in Greece}

The hotel complex "Akti Lakopetra" is situated at the Northwest end of the Peloponnese, about $10 \mathrm{Km}$ Eastward of the entrance of the Patraic gulf. The complex extends for about $290 \mathrm{~m}$ along the shore.

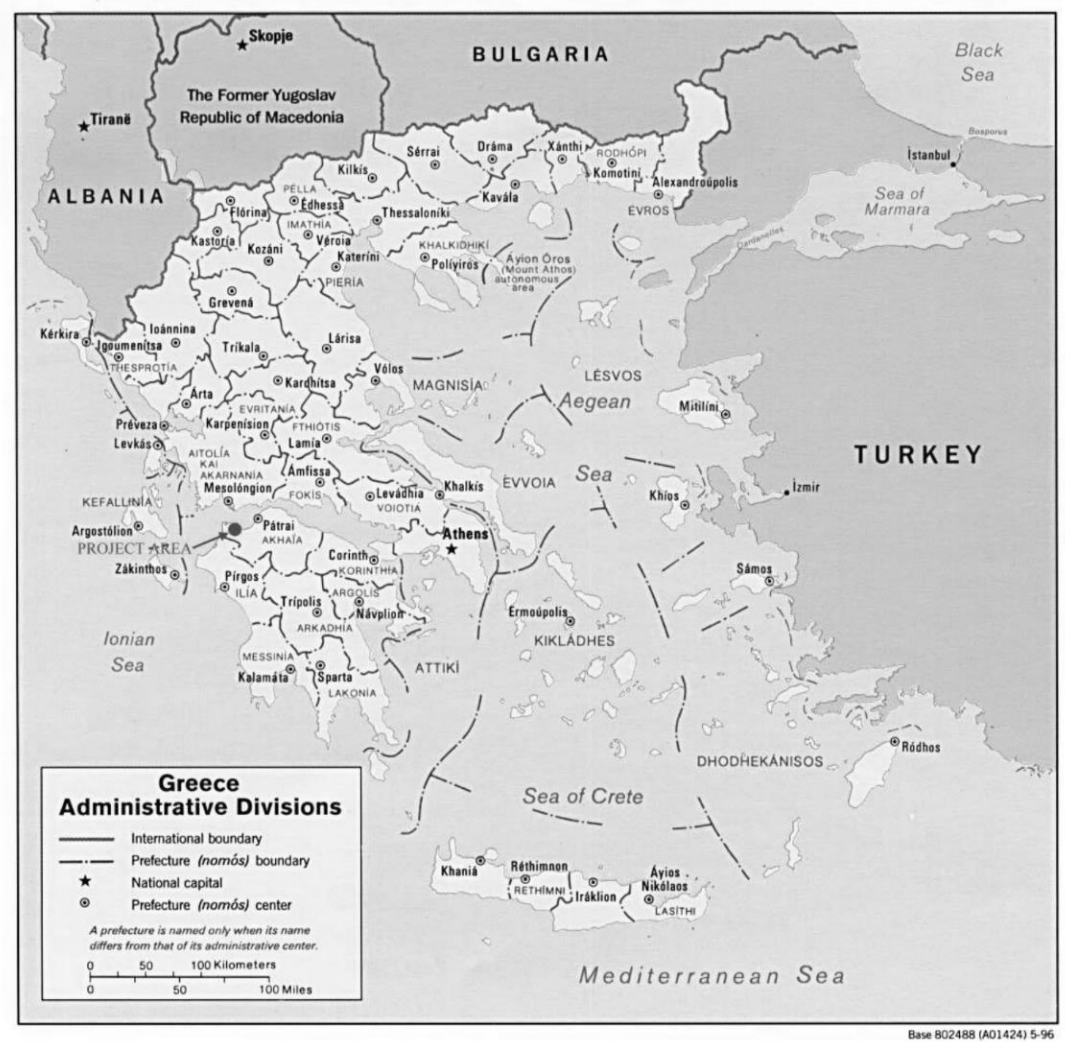

Figure 1: $\quad$ Project area at North Peloponnese.

The beach in front of the hotel as well the sea bottom is sandy. The sea depths increase smoothly from the shore with a slope of $2-3 \%$. The geology of the wider 
project area indicates the presence of Holocene type alluvial sediments formed by river and water stream discharges into the coastal system as well as sediment transport coastal mechanisms due to wave action. These sediments consist mainly of granular material such as sand and gravel.

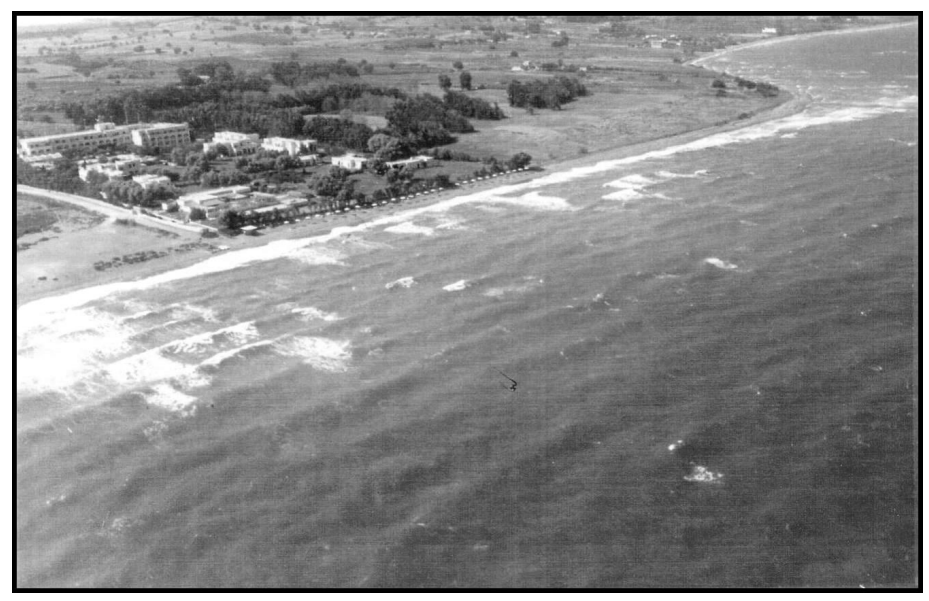

Figure 2: View of the beach before the construction of the breakwaters.

Wind generated waves inside the Patraic gulf, with a significant height of $2,5 \mathrm{~m}$ reach at the hotel beach area. As the waves approach to the shore they break and because of the smooth slope of the sea bed the breaking zone is quite extensive having a width of several tens of meters. Wave-breaking initiates erosion processes. Thus the wave action is considered as the main responsible factor for the gradual reduction of the coastal width. Onshore sediment feeding of the coast has been also diminished due to a coastal road construction. The continuing erosion process was expected to result even to complete loss of the beach within the next few years. The beach is considered very important for the Hotel enterprise as to be characterized as an asset for it. Recreational activities and sports take place on the beach during the summer touristic period and the sea front is the main attraction area for the Hotel residents who play and swim. The policy option was to extend the width of the beach with the construction of an offshore breakwater system.

For the efficient protection of the shoreline against the incoming waves, three detached breakwaters of $70 \mathrm{~m}$ length each with $40 \mathrm{~m}$ openings between them were constructed at a distance of $125 \mathrm{~m}$ from the shore. The depth at the toe of the breakwaters is approximately $3.30 \mathrm{~m}$ thus they lie outside the limits of the breaking zone. The cross-section of the breakwaters has been armored with natural rock of 1,5-2,5 ton weight and the in-between layers and core from rocky materials. The crest width was $3.0 \mathrm{~m}$ at the head of the structure and the crest height at $+0.70 \mathrm{~m}$ from the mean sea level. The crest elevation of the works has been kept low in order not to heavily obstruct the sea view from the beach. 


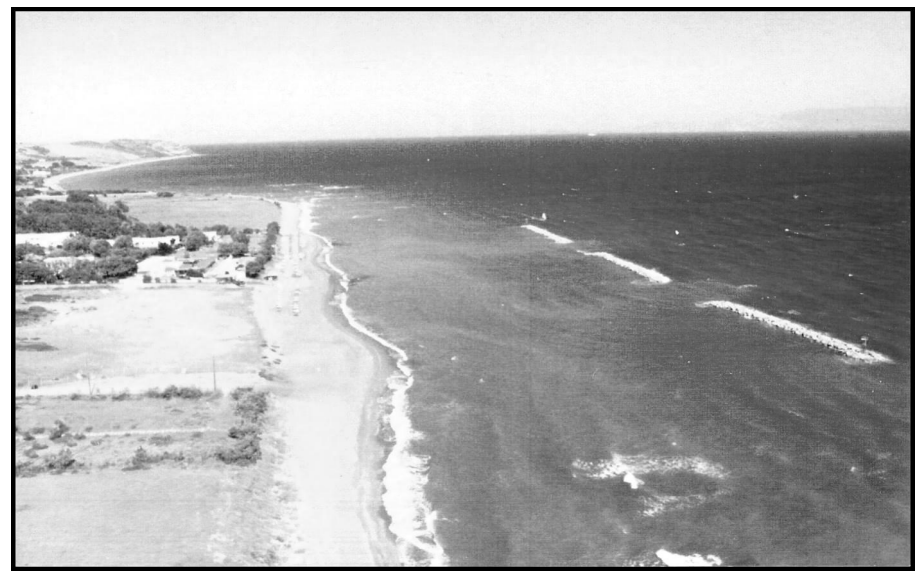

Figure 3: View of the beach after the construction of the breakwaters.

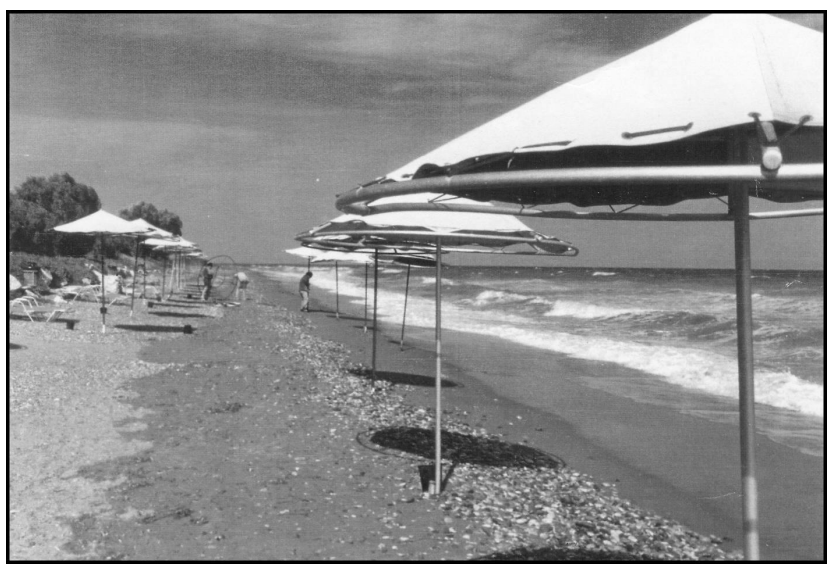

Figure 4: West view of the beach before the construction of the breakwaters.

After the construction of the offshore breakwaters the coast erosion stopped, and the erosion mechanism was reversed leading to formation of a new coastal zone due to accretion of sediments in the lee side of the breakwaters. The coastline response was very impressive. The construction works were finished early in spring just before the beginning of the touristic period and within the same summer the width of the beach was almost doubled.

Beach regeneration was fully successful but it should be noted that the low crest height although more acceptable aesthetically reduces the structure efficiency for wave attenuation, resulting to wave induced disturbance at the protected lee side area. 


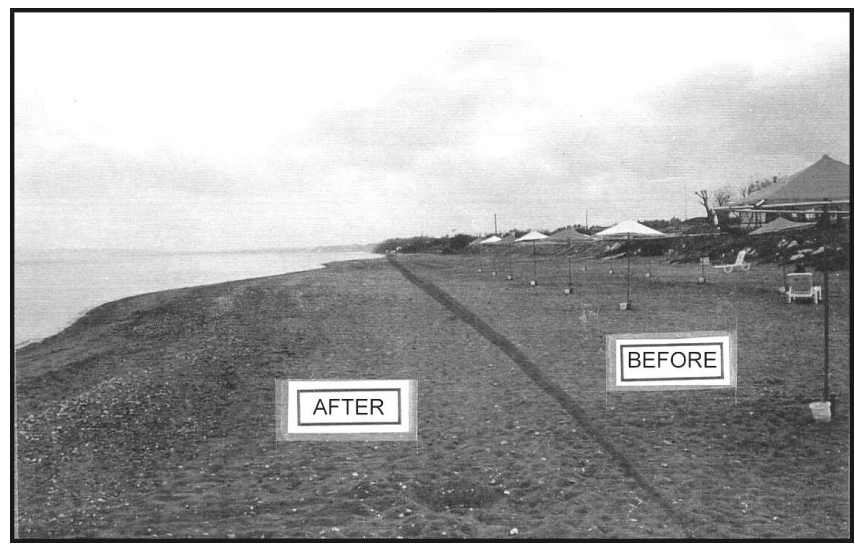

Figure 5: East view of the beach after the construction of the breakwaters.

\section{2 "Alaminos Estate" resort in Cyprus}

The "Alaminos Estate" is located between the capes of Pentaschinos and Petounta along the Southeast coast of Cyprus.

The land behind the shoreline is relatively flat without any significant morphological changes. On the contrary, beach slope is almost vertical measuring a height of $5.0 \mathrm{~m}$. At the toe of the slope loose alluvial sediment exist with a great percentage of gravel. The sea bottom is mostly sandy with small rocky areas. The sea depths increase smoothly from the shore with a slope of $1,5-2 \%$.

Wind generated waves reach the coast, with a significant height up to $6,0 \mathrm{~m}$ and cause serious erosion problems. The construction of a coastal protection system was decided in order to avoid the extended coastal erosion at the shore lying in front of the Company's Property and on the other hand to develop a wide sandy beach and provide the appropriate calm conditions for swimming and general recreation activities.

Due to the long shoreline stretch at Alaminos area, a multiple breakwater system has been designed. The system consists of five detached offshore breakwaters with relative low crest elevation (for environmental reasons), allowing partial overtopping of the structures by the incident waves.

The main design characteristics of the detached breakwater system are:

- $\quad$ The length of each breakwater has been set to $140 \mathrm{~m}$.

Only the east breakwater has a total length of $220 \mathrm{~m}$, since a small sheltered basin is foreseen for accommodation of small crafts.

Opening (gap) between breakwaters is $25-30 \mathrm{~m}$.

$-$

Breakwater crest elevations are placed at $+0.50 \mathrm{~m}$. (related to

M.W.L.) while the corresponding one of the east breakwater at $+2.0 \mathrm{~m}$. (related to M.W.L.).

\section{- $\quad$ Crest width is $3.70 \mathrm{~m}$.}


Angle between the longitudinal breakwater axis and mean shoreline direction is $13^{\circ}$.

- Both internal and external breakwater rubble mounds slopes formed equal to 1,0: 1,5 (vertical: horizontal).

The breakwater armouring consists of two (2) quarry stone layers, with weight gradation varying between 3.0 - 5.0tons.

- $\quad$ Special care has been given at the system design layout (location of breakwater at the nearshore zone), to prevent tombolo formation.

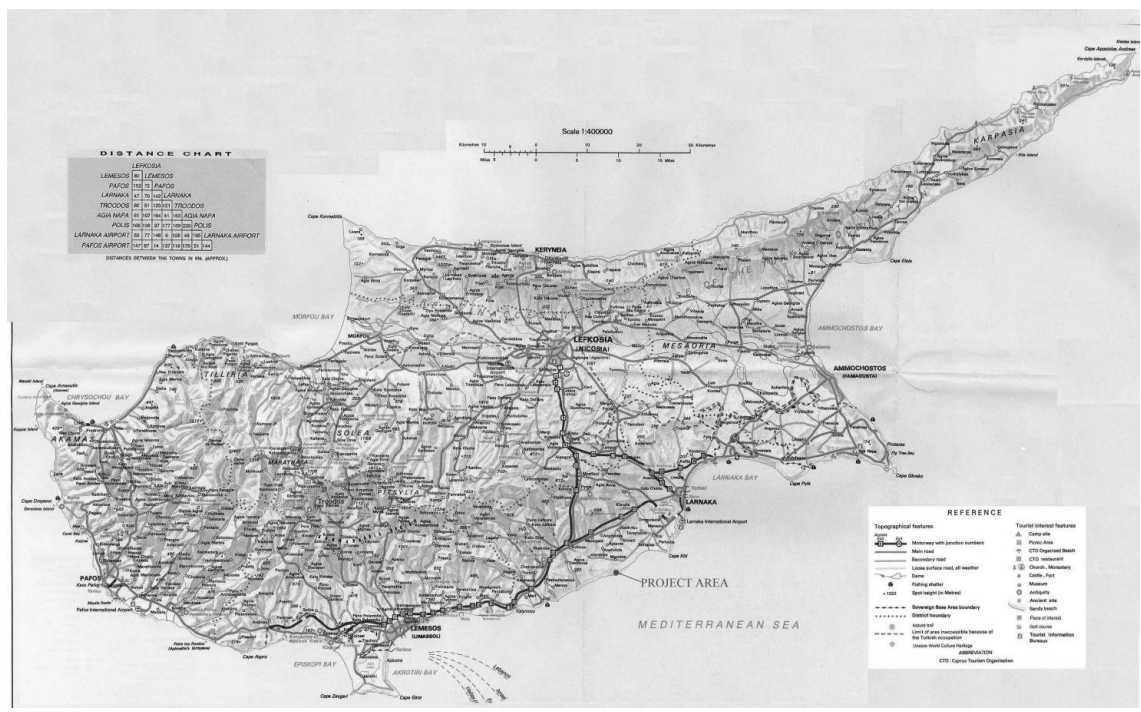

Figure 6: $\quad$ Project area at South coast of Cyprus.

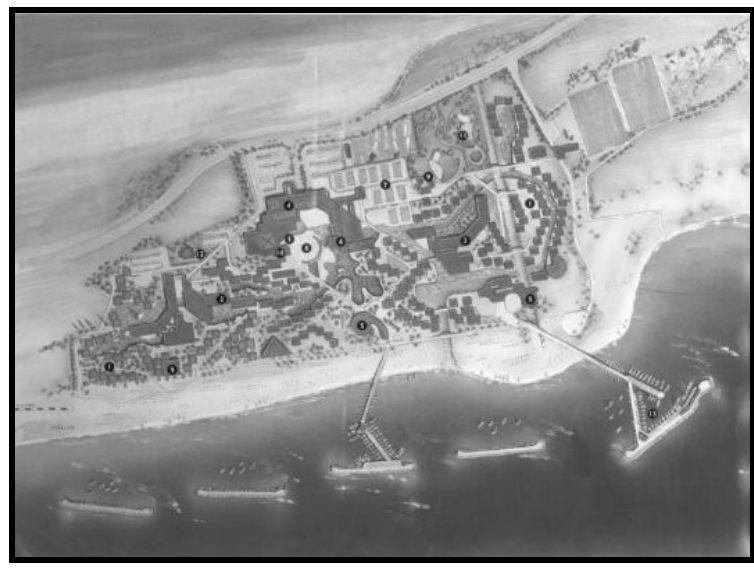

Figure 7: The "Alaminos Estate" Resort and the coastal protection works (Artistic view). 


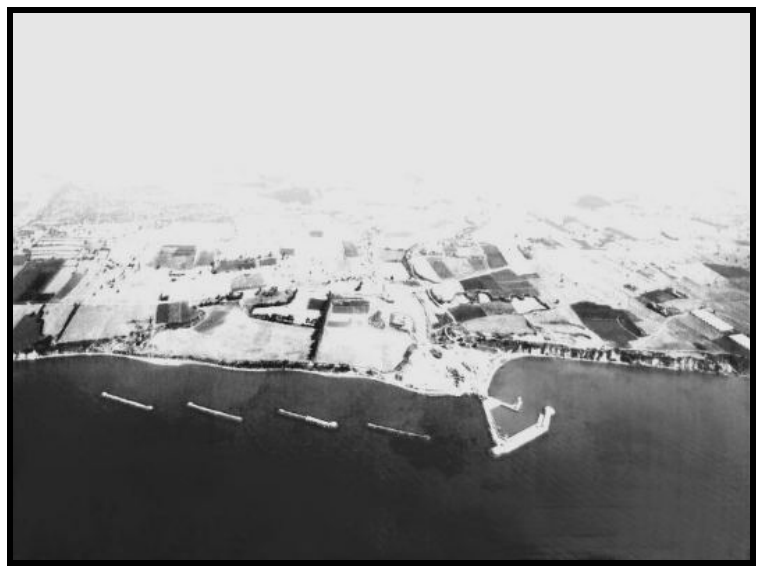

Figure 8: Arial view after the construction of the offshore breakwaters.

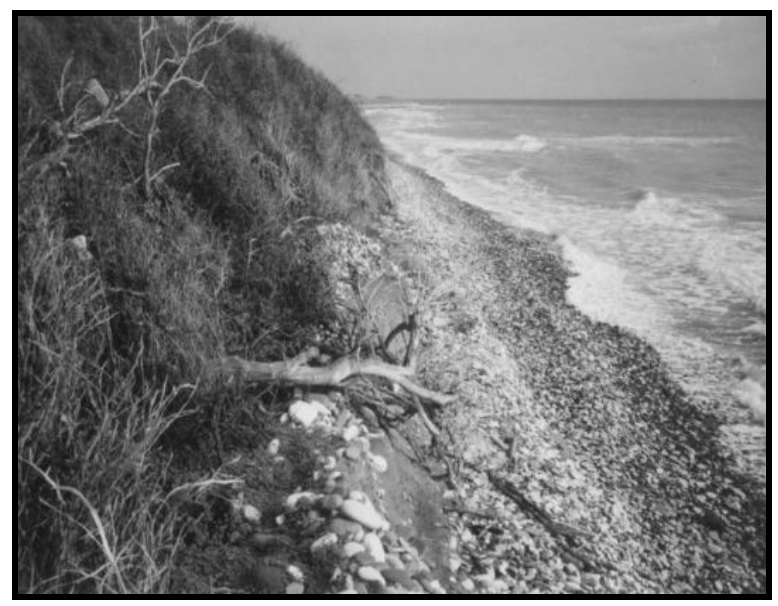

Figure 9: Shore profile before the construction of the coastal structures.

From the system monitoring during its operation period the following observations have been made:

- Breakwaters cause significant decrease in the wave energy propagated from $\mathrm{S}$ and $\mathrm{SW}$ sectors (the prevailing ones according to the wave data). As a result, a remarkable increase to the sediment transport directed towards the coast has been observed.

- A significant reduction at longshore current velocities has been observed, especially for those generated by waves propagating from the $\mathrm{S}$ and $\mathrm{SW}$ directions, causing corresponding reduction to the sand carrying capacity along the shoreline at the breakwaters lee side. 


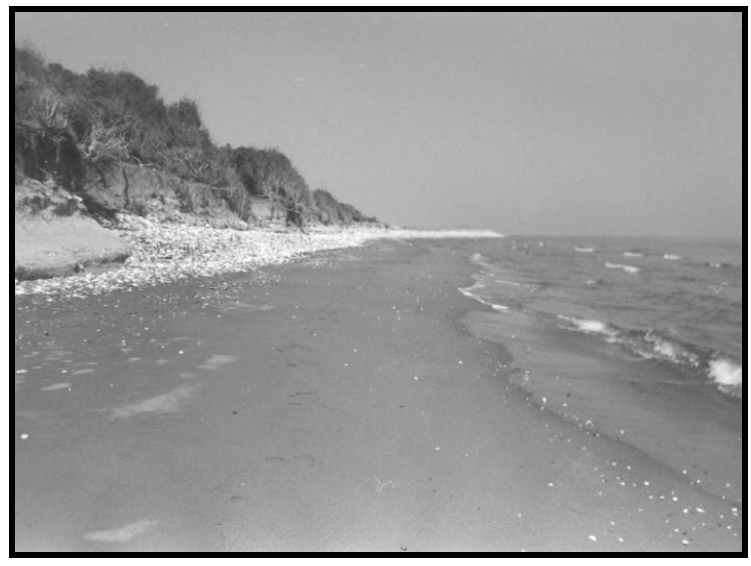

Figure 10: Shore profile after the construction of the coastal structures.

- Initially stabilization of the existing beach occurred, while at a later stage a new sandy beach started gradually to develop, with sandy projections at the corresponding lee sides of each breakwater. The maximum width of these projections is approximately $40 \mathrm{~m}$.

- A net seaward current (rip current) moving through the breakwater gaps, with maximum velocities reaching at $0,20 \mathrm{~m} / \mathrm{sec}$. These low velocities ensure that there is not any significant sediment movement directed seaward and furthermore that the breakwaters could provide secure conditions for swimming and other recreational activities at their lee side.

- The water condition will be excellent for bathers.

\section{Conclusions}

Offshore breakwaters are constructed in order to reduce wave energy or modify the wave climate at the lee of the structures and enhance sediment transport patterns so as to improve beach width through creation of salients. Two case studies are presented in Greece and Cyprus where offshore breakwater systems have been successfully operated, leading to hotel beach upgrading. It should be noted that the low-crest structures are environmentally more acceptable but do not allow for large wave attenuation at their sheltered area. 